\title{
Changes in the Transmission Dynamic of Chikungunya Virus in Southeastern Senegal
}

\author{
Abdourahmane Sow ${ }^{1,2,3, *}$, Birgit Nikolay 4,5,6, Oumar Faye ${ }^{1}$, Simon Cauchemez ${ }^{4,5,6}$, \\ Jorge Cano ${ }^{7}$, Mawlouth Diallo ${ }^{8}$, Ousmane Faye ${ }^{1}$, Bakary Sadio ${ }^{1}$, Oumar Ndiaye ${ }^{1}$, \\ Scott C. Weaver ${ }^{9}$, Anta T. Dia ${ }^{2}$, Amadou Alpha Sall ${ }^{1}$ and Denis Malvy ${ }^{3}$
}

1 Institut Pasteur Dakar, Arbovirus and viral Hemorrhagic Fevers Unit, 12500 Dakar, Senegal; Oumar.faye@pasteur.sn (O.F.); Ousmane.Faye@pasteur.sn (O.F.); Bakary.Sadio@pasteur.sn (B.S.); Oumar.Ndiaye@pasteur.sn (O.N.); Amadou.Sall@pasteur.sn (A.A.S.)

2 Institut Santé et développement (ISED), Université Cheikh Anta Diop, 12500 Dakar, Senegal; diagodia@hotmail.fr

3 Inserm U1219 University of Bordeaux, 33063 Bordeaux, France; denis.malvy@chu-bordeaux.fr

4 Mathematical Modelling of Infectious Diseases Unit, Institut Pasteur, 75015 Paris, France; birgit.nikolay@pasteur.fr (B.N.); simon.cauchemez@pasteur.fr (S.C.)

5 Centre National de Recherche Scientifique (CNRS), URA3012, Paris, France

6 Center of Bioinformatics, Biostatistics and Integrative Biology, Institut Pasteur, 75015 Paris, France

7 Faculty of Infectious Diseases and Tropical Medicine, London School of Hygiene \& Tropical Medicine, London WC1E7HT, UK; jcano.ortega@lshtm.ac.uk

8 Institut Pasteur Dakar, Medical Entomology Unit, 12500 Dakar, Senegal; Mawlouth.Diallo@pasteur.sn

9 Institute for Human Infections and Immunity, World Reference Center for Emerging Viruses and Arboviruses and Department of Microbiology and Immunology, University of Texas Medical Branch, Galveston, TX 77555, USA; sweaver@utmb.edu

* Correspondence: asow20@gmail.com; Tel.: +226-66894712

Received: 23 October 2019; Accepted: 24 January 2020; Published: 10 February 2020

\begin{abstract}
In Senegal, chikungunya virus (CHIKV) is maintained in a sylvatic cycle and causes sporadic cases or small outbreaks in rural areas. However, little is known about the influence of the environment on its transmission. To address the question, 120 villages were randomly selected in the Kedougou region of southeastern Senegal. In each selected village, 10 persons by randomly selected household were sampled and tested for specific anti-CHIKV IgG antibodies by ELISA. We investigated the association of CHIKV seroprevalence with environmental variables using logistic regression analysis and the spatial correlation of village seroprevalence based on semivariogram analysis. Fifty-four percent (51\%-57\%) of individuals sampled during the survey tested positive for CHIKV-specific IgG. CHIKV seroprevalence was significantly higher in populations living close to forested areas (Normalized Difference Vegetation Index (NDVI), Odds Ratio (OR) $=1.90(1.42-2.57)$ ), and was negatively associated with population density $(\mathrm{OR}=0.76(0.69-0.84))$. In contrast, in gold mining sites where population density was $>400$ people per $\mathrm{km}^{2}$, seroprevalence peaked significantly among adults $(46 \%(27 \%-67 \%))$ compared to all other individuals $(20 \%(12 \%-31 \%))$. However, traditional gold mining activities significantly modify the transmission dynamic of $\mathrm{CHIKV}$, leading to a potential increase of the risk of human exposition in the region.
\end{abstract}

Keywords: Chikungunya; spatial autocorrelation; environmental risk; gold mining; Senegal

\section{Introduction}

Chikungunya virus (CHIKV) is a mosquito-borne alphavirus that belongs to the Togaviridae family [1]. It was first isolated in 1953 from the serum of a febrile patient during an epidemic in the 
Newala district of Tanzania [2,3]. Acute CHIKV infection in humans can cause a flu-like syndrome associated with a rash and severe arthralgia [4-8]. In sub-Saharan Africa, CHIKV is maintained in a sylvatic cycle involving non-human primates as reservoir hosts $[9,10]$ and forest-dwelling mosquitoes [11,12]. Sylvatic vectors can be responsible for sporadic cases or small outbreaks among humans living in rural areas $[9,13,14]$. In urban areas, CHIKV is transmitted among humans by Aedes aegypti and Aedes albopictus mosquitoes [15].

Since the outbreak in Tanzania in 1952, CHIKV outbreaks have been reported in Africa, Asia, and Latin America between the 1960s and 2000s [16]. Recently, CHIKV was recognized as an emerging arbovirus with an important public health impact after major epidemics occurred in 2004 in several countries (Kenya, Comores, and islands in the Indian Ocean). The largest outbreak in the Indian Ocean basin occurred in La Reunion Island in 2005, with 300,000 infected cases, and an attack rate of about 35\% [17]. In addition to major epidemics in Asia from 2005 to 2008, a significant outbreak occurred in Italy in 2007, and sporadic autochthonous cases have been detected in northeastern Italy and southeastern France, as well as in the USA among travelers from India in 2006 [18-21]. The spread of CHIKV in Europe and parts of Asia was attributed to the spread of the anthropophilic mosquito Ae. albopictus outside of Asia via international transportation, and the global movement of viremic individuals [22-24], emphasizing CHIKV as a re-emerging threat to global public health.

In Senegal, CHIKV was first isolated from a bat in 1962 [25,26], and since then, sporadic human cases and outbreaks were regularly reported [14,19,27-29]. Since 1972, the Pasteur Institute of Dakar has implemented an entomological surveillance program in the Kedougou area, located on the border of Guinea, in southeastern Senegal. In this area, CHIKV was repeatedly isolated from Aedes furcifer, Aedes luteocephalus, and Aedes taylori [9,29-32]. Amplifications of CHIKV have been detected at approximately 5-year intervals. This interval is hypothesized to be the time necessary for the turnover of susceptible vertebrate hosts, mainly nonhuman primates [6]. In 2009, a CHIKV zoonotic amplification occurred in the Kedougou region, detected in both humans and mosquitoes. Indeed, 20 confirmed human cases were reported in the Kedougou and Saraya districts, mainly in gold mining sites. In parallel, 42 CHIKV-infected mosquito pools were obtained by RT-PCR from September to December 2009, mainly from Ae. furcifer (16 pools), Ae. taylori (5 pools), and Ae. luteocephalus (5 pools) [33].

Despite active sylvatic circulation of CHIKV in the Kedougou region, limited information is available about its impact on human health and its interaction with environmental conditions. To address these questions, we conducted a serosurvey in 2012 following the last detected virus amplification in 2009. Here, we report the results of the serosurvey implemented in Kedougou, southeastern Senegal.

\section{Materials and Methods}

\subsection{Serological Study}

The study was carried out in the Kedougou region, located in the extreme southeast of Senegal, between $12^{\circ} 33^{\prime}$ north latitude and $12^{\circ} 11^{\prime}$ west longitude (Figure 1A,B). It extends over an area of $16,896 \mathrm{~km}^{2}$ with an estimated population of 153,476 inhabitants, of which 55\% are under 20 years of age, with an average density of 8 persons per $\mathrm{km}^{2}$ [34]. The population is predominantly rural $(84 \%)$, and ethnically diverse. On average, annual rainfall in the area is estimated between 1200 and $1300 \mathrm{~mm}$. Agriculture remains the principal economic activity, but traditional gold mining has increased considerably, leading to massive human migration and important eco-environmental changes.

The sampling method was based on a two-level cross-sectional randomized cluster sampling adapted from the WHO procedure. The sampling frame was the list of villages drawn up for the 2002 national census. The Kedougou region was first divided into 3 districts. For each district, 40 villages were randomly selected using the cumulative total method. In each of the selected villages, 10 persons by randomly selected household were sampled. From each consented individual, $5 \mathrm{~mL}$ of intravenous blood was taken. Samples were centrifuged, and serum aliquoted, and sent in liquid nitrogen to the Dakar Pasteur Institute for anti-CHIKV IgG antibodies ELISA, according to the method described by 
Traore-Lamizana et al. [35]. Briefly, indirect IgG ELISA testing was performed on Microplate ELISA 96-well Maxisorp. After a coating step with CHIKV mouse hyperimmune ascitic fluid, followed by CHIKV antigen capture, samples were added, and specific antibody-antigen complexes were revealed by an anti-human IgG horseradish peroxidase conjugated antibody (KPL, USA). An ELISA microplate reader showed the Optical Density (OD) and sera as positive samples if the OD was $\geq 0.20$ and the ratio $(R)$ between the sample and the negative control was $>2$.

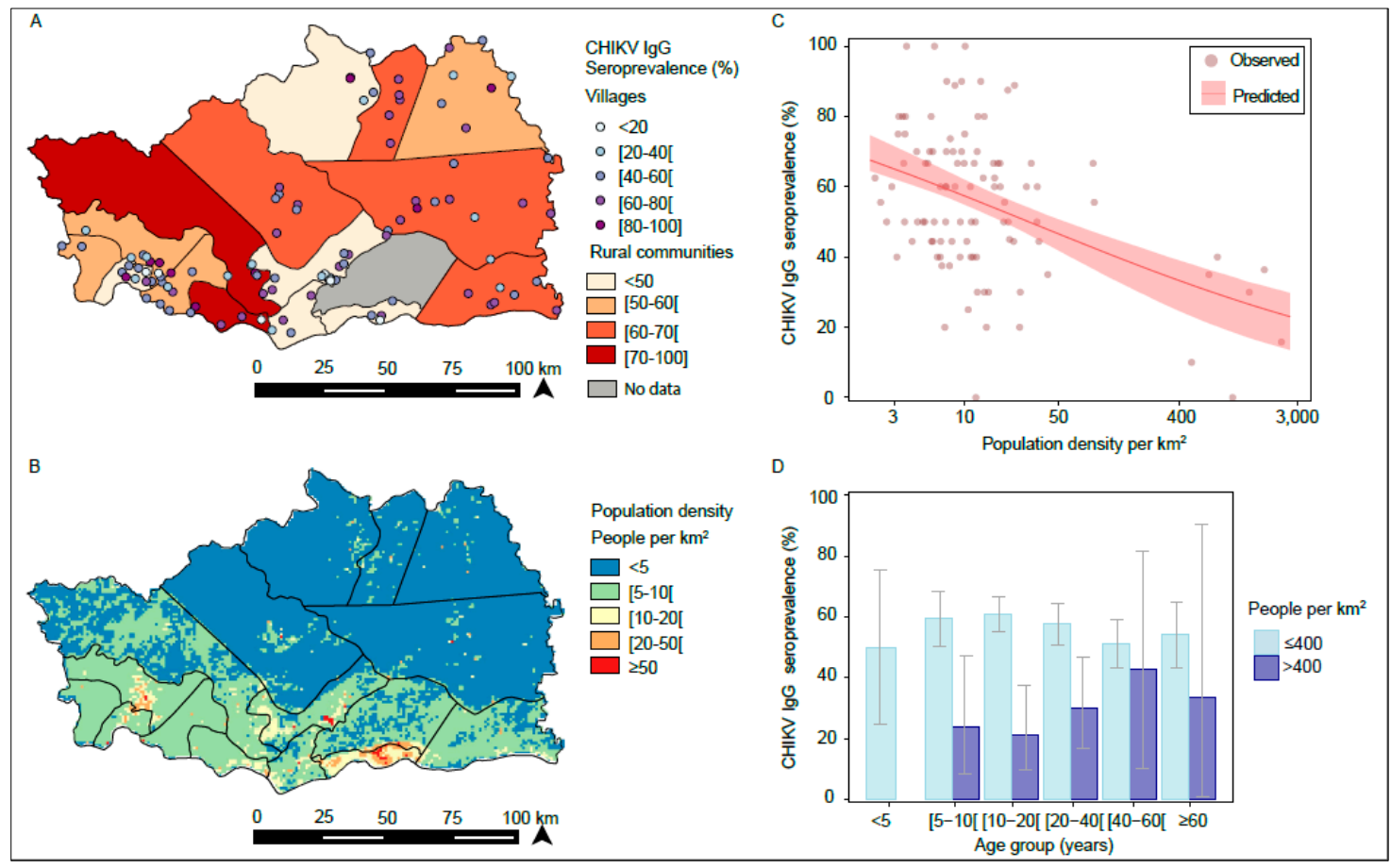

Figure 1. Spatial variation in chikungunya virus (CHIKV) IgG seroprevalence. (A) Seroprevalence by village and rural community. (B) Spatial variation in population density. (C) Observed and predicted seroprevalence by population density. The $95 \%$ confidence interval (CI) of the prediction was obtained by bootstrap (2000 iterations). (D) Age patterns by population density ( $\leq 400$ vs. $>400$ people per $\mathrm{km}^{2}$ ).

\subsection{Environmental Data}

A suite of environmental, topographical, and demographic datasets was used to explore potential drivers of CHIKV outbreaks in the study area. From the Moderate Resolution Imaging Spectroradiometer (MODIS) [36] product, we downloaded global MOD13Q1 data, which include vegetation indices such as the Normalized Difference Vegetation Index (NDVI), the Enhanced Vegetation Index (EVI), and the mid-infrared band (MIR). The NDVI and EVI are effective for quantifying green vegetation but the EVI was specifically developed to be more sensitive to changes in areas having high biomass, while MIR has been found to be useful to discriminate water surfaces [37]. Forest cover for the study area was obtained from the Global Forest Change project (University of Maryland, Maryland, USA) [38]. The elevation dataset at $250 \mathrm{~m}$ resolution was derived from a gridded digital elevation model produced by the Shuttle Radar Topography Mission (SRTM) [39]. Finally, gridded maps at $100 \mathrm{~m}$ resolution of estimated population density for Senegal, in 2010 and 2015, were obtained from the World Pop project [39]. Environmental, topographic, and demographic data were extracted for village point locations as average values over a buffer zone of $1 \mathrm{~km}$ radius. We further assessed sensitivity of estimates to buffer size by repeating the analysis with a buffer zone of a $3 \mathrm{~km}$ radius to account for movement of individuals around village locations. 


\subsection{Statistical Analysis}

\subsubsection{Descriptive Analysis}

Age was classified as $<5,5$ to 9,10 to 19,20 to 39,40 to 59 , and $\geq 60$ years. Associations of seroprevalence with the age and sex of individuals were investigated by logistic regression analysis, and statistical significance was assessed with a likelihood ratio test. The models included random intercepts for villages and rural communities to adjust for clustering of surveyed individuals. Confidence intervals of seroprevalence by sex or age group were obtained based on the exact binomial method. We included a sex-age interaction term to explore potential greater exposure to infections on certain groups (i.e., male adults be more exposed during their activities outside their resident villages), considering that age groups reflect different occupational activities $(<20,20$ to 59 , and $\geq 60$ years), and stratified by population density (locations with $\leq 400$ and $>400$ people per $\mathrm{km}^{2}$ ).

\subsubsection{Spatial Patterns of Seroprevalence}

We aggregated individuals by villages and rural communities to assess the spatial variation in seroprevalence levels. We investigated the spatial correlation of village seroprevalence based on semivariogram analysis using the geoR package.

\subsubsection{Environmental Risk Factors}

We first investigated the association of CHIKV seroprevalence with environmental variables by univariable logistic regression analysis, including random intercepts for villages and rural communities. We classified environmental variables into quintiles to assess departure from linearity in associations and included these as categorical terms in the models. For each variable, we compared the model fit to a model including the variable as a continuous term. The decision to include variables as categorical or continuous terms was based on the lowest Akaike information criterion (AIC). Fo variables associated with seroprevalence that were highly correlated (Pearson's $r>0.7$ ), we performed a preliminary variable selection based on the lowest likelihood ratio test (LRT) $p$-values and lowest AIC. Due to convergence problems when including all variables simultaneously, we chose a forward model selection approach, starting with the variable with the lowest $p$-value and lowest AIC, adding additional variables in order of increasing $p$-values and AIC. Variables were retained in the model if significantly associated $(p \leq 0.05)$. Random intercepts were retained in the final model if these were significantly associated $(p \leq 0.05)$ and improved the model fit.

To assess spatial patterns in the unexplained variation of seroprevalence by villages, we investigated spatial correlation of village random-effects by semivariogram analysis, as described above. Additionally, we compared model fit of the selected logistic regression model to a geostatistical model that additionally accounted for spatial correlation between village random effects.

Basic statistical analysis was performed using the $\mathrm{R}$ computing environment, and parameters of geostatistical models were estimated using Bayesian methods implemented in Winbugs [40].

\section{Results}

\subsection{Serological Investigation for CHIKV IgG in 2012}

In total, 998 individuals living in 101 villages and 15 rural communities in the Kedougou region were tested for anti-CHIKV IgG. The age of tested individuals ranged from 1 to 99 years (median 21, IQR $12-41)$ and $56 \%$ of tested individuals were male. Fifty-four percent of individuals (51\%-57\%) were positive for CHIKV IgG. Seroprevalence did not vary significantly by sex (males 53\% (95\% confidence values $49-57)$; females $55 \%(50 \%-60 \%) ; p=0.522)$ or age-group $(p=0.485)$ (Figure 2$)$. 


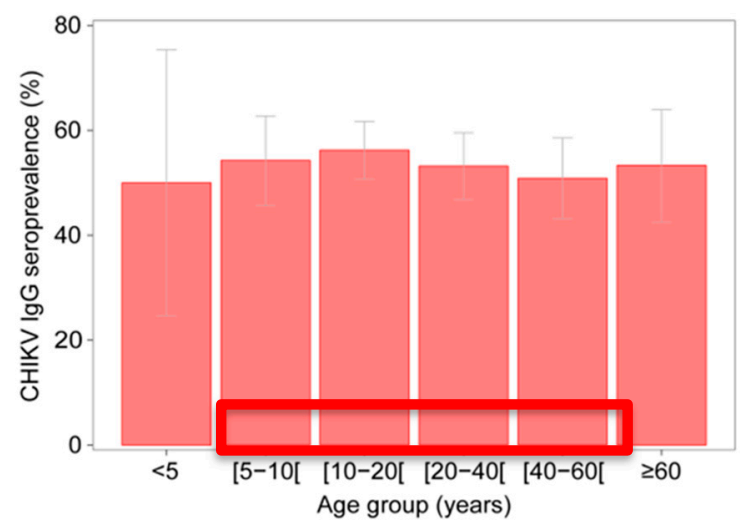

Figure 2. Seroprevalence by age group and exact binomial 95\% confidence intervals.

\subsection{Spatial Variation in CHIKV IgG Seroprevalence}

Seroprevalence against CHIKV varied among villages and rural communities in the study area (Figure 1A); however, village seroprevalence levels were not spatially correlated (File S1, Figure A1). Tables 1 and A1 in Appendix A show that in univariate analysis, CHIKV seroprevalence was significantly higher in populations living in areas close to a forest with a large amount of vegetation, compared to those living in areas with less or without vegetation (NDVI, Odds Ratio (OR) $=1.90(1.42-2.57)$ ).

Table 1. Univariable analysis of the association between CHIKV seroprevalence and environmental variables. The models were adjusted for clustering of individuals in villages and rural communities (random intercept).

\begin{tabular}{|c|c|c|c|}
\hline Environmental Variables & OR $(95 \% C I)$ & LRT $p$-Value & AIC \\
\hline EVI_max (per 0.1 increase) & $1.54(1.16 ; 2.02)$ & 0.002 & 1354 \\
\hline EVI_mean (per 0.1 increase) & $2.23(1.44 ; 3.47)$ & $<0.001$ & 1351 \\
\hline EVI_sd (per 0.01 increase) & $1.14(1.03 ; 1.27)$ & 0.010 & 1357 \\
\hline NDVI_max (per 0.1 increase) & $1.90(1.42 ; 2.57)$ & $<0.001$ & 1348 \\
\hline NDVI_mean (per 0.1 increase) & $1.85(1.35 ; 2.52)$ & $<0.001$ & 1350 \\
\hline NDVI_sd (per 0.01 increase) & $1.16(1.03 ; 1.30)$ & 0.012 & 1357 \\
\hline MIR_max (per 0.1 increase) & $0.68(0.35 ; 1.35)$ & 0.258 & 1362 \\
\hline MIR_mean (per 0.1 increase) & $0.22(0.10 ; 0.51)$ & $<0.001$ & 1352 \\
\hline MIR_sd (per 0.01 increase) & $1.02(0.82 ; 1.28)$ & 0.829 & 1363 \\
\hline Distance to water bodies $(\mathrm{km})$ & $1.01(1.00 ; 1.03)$ & 0.048 & 1360 \\
\hline Distance to rivers $(\mathrm{km})$ & $1.02(0.99 ; 1.05)$ & 0.202 & 1361 \\
\hline Population density per $\mathrm{km}^{2}$ (log-transformed) & $0.76(0.69 ; 0.84)$ & $<0.001$ & 1340 \\
\hline Slope (degree) & $1.12(0.98 ; 1.29)$ & 0.089 & 1360 \\
\hline Altitude (meters) & $1.00(1.00 ; 1.00)$ & 0.937 & 1363 \\
\hline Forest area (proportion, per 0.1 increase) & $1.06(0.99 ; 1.13)$ & 0.081 & 1360 \\
\hline Distance to forest $(\mathrm{km})$ & $0.86(0.76 ; 0.98)$ & 0.023 & 1358 \\
\hline Accessibility (travel time to city per hour increase) & $1.00(1.00 ; 1.00)$ & 0.985 & 1363 \\
\hline \multicolumn{4}{|l|}{ Random Intercepts: } \\
\hline Village only & NA & 0.003 & 1362 \\
\hline Rural community only & NA & 0.094 & 1368 \\
\hline Village and rural & NA & $<0.001$ & 1361 \\
\hline
\end{tabular}

NDVI: Normalized Difference Vegetation Index; EVI: Enhanced Vegetation Index; MIR: mid-infrared band; OR: Odds Ratio, CI: confidence interval; LRT: likelihood ratio test; AIC: Akaike information criterion.

The model that best explained the observed spatial variation in seroprevalence was based on population density (Figure 1B) and accounted for clustering of individuals in villages (village random effects). Indeed, seroprevalence was negatively associated with population density, so that for each 
one-unit increase in population density at the log-scale, the seroprevalence decreased by an Odds Ratio (OR) of 0.76 (0.69-0.84) (Tables 2 and A2).

Table 2. Multivariable analysis of the association between CHIKV seroprevalence and environmental variables. The models were adjusted for population density (log-scale) and clustering of individuals in villages (random intercept).

\begin{tabular}{cccc}
\hline Environmental Variables & OR $\mathbf{( 9 5} \% \mathbf{C I})$ & LRT $p$-Value & AIC \\
\hline Population density per $\mathrm{km}^{2}$ (log-transformed) & $0.76(0.69 ; 0.84)$ & 0.008 & 1338 \\
NDVI_max (per 0.1 increase) & $1.17(0.76 ; 1.81)$ & 0.485 & 1340 \\
Distance to forest $(\mathrm{km})$ & $0.97(0.86 ; 1.10)$ & 0.614 & 1340 \\
Distance to water bodies $(\mathrm{km})$ & $1.00(0.99 ; 1.01)$ & 0.735 & 1340 \\
\hline
\end{tabular}

NDVI: Normalized Difference Vegetation Index, OR: Odds Ratio, CI: confidence interval, LRT: likelihood ratio test, AIC: Akaike information criterion.

This translates, for example, into a predicted seroprevalence of $57 \%(55 \%-62 \%)$ at a population density of 10 persons per $\mathrm{km}^{2}$, compared to $32 \%(23 \%-38 \%)$ at a population density of 500 persons per $\mathrm{km}^{2}$ (Figure 1C). Village random effects were not spatially correlated, and including spatial dependency did not improve model fit (File S1, Figure A1).

Contrary to Figure 1D, among individuals living in villages where population density was $>400$ people per $\mathrm{km}^{2}$ (i.e., seven villages in the rural community of Bandafassi, which are the main sites of traditional gold mining), seroprevalence against CHIKV peaked among adults; in particular, it was significantly higher among male adults $20-59$ years old at $46 \%(27 \%-67 \%)$, compared to all other individuals $(20 \%(12 \%-31 \%) ; p=0.013)$ ( Table A3). There was suggestive evidence for an interaction between sex and age ( $\left.p_{\text {interaction }}=0.098\right)$.

Among individuals living at population densities $\leq 400$ people per $\mathrm{km}^{2}$, seroprevalence among male adults did not differ significantly from other individuals $(p=0.091)$ and no interaction between age and sex was detected $\left(p_{\text {interaction }}=0.766\right)$.

\section{Discussion}

Two years after a chikungunya outbreak in the Kedougou region [41], our survey showed that over $50 \%$ of studied individuals had a history of CHIKV infection. Seroprevalence was homogeneously distributed over all age ranges, including very young children, suggesting a simultaneous and recent exposure of the population to CHIKV circulation. Distinctly, continuous endemic circulation of CHIKV within this population would have led to a significant age pattern with increasing seroprevalence by age.

Seroprevalence against CHIKV was highest in remote areas with low population density. Indeed, individuals living in those areas were 1.24 times more likely exposed to CHIKV than those living in areas with a high population density. This can be explained by CHIKV transmission through spillover via sylvatic mosquitoes, such as Ae. furcifer, which is more frequent in rural areas close to the forest galleries, and which was identified as the main vector during the 2009 epidemic [42]. Indeed, the analysis of adult mosquito collections undertaken in eight localities in the region, including the main gold mining sites (Hafia, Wassangran, Ndebou, Matakossi, Bondala, Tenkoto, Velingra, and Bantako), revealed a high abundance of Ae. furcifer in these localities, except for Bantako, which exhibited a low abundance. While in Bantako, the species represented 7.9\% of the mosquito fauna collected, in other localities the abundance ranged between $40.5 \%$ and $81.7 \%$ (Diallo, unpublished data). In addition, the univariate analysis showed that populations living close to the forest and to rivers (forest galleries) were significantly more exposed than the others (Table 1).

Although overall seroprevalence was low in the Bandafassi rural community, CHIKV seroprevalence was significantly higher in gold mining sites where the population density was relatively high, especially among male adults. In addition, during the outbreak in 2009-2010, those villages harboring such gold mining sites were most affected by CHIKV [43]. A similar pattern was also observed during the 
CHIKV outbreak in 2015, where confirmed cases in the Saraya district clustered in villages where the main gold mining sites were located (unpublished data). This suggests that traditional gold mining, by attracting thousands of indigenous and foreign populations to remote rural areas, particularly close to the forest galleries, may increase exposure of humans to CHIKV through spillover from the enzootic cycle. Moreover, environmental changes linked to human activity in sites with a high human concentration favor the development of domestic larval sites [43]. However, to better understand the distribution of CHIKV infection in the region, other potential risk factors that could have led to the higher risk, such as mosquito vector populations and the mobility of the gold miners, need to be investigated in the future. Although no chikungunya cases have been previously reported in the Salemata district, the seroprevalence rate was found to be high $(>50 \%)$. This finding suggests either CHIKV circulation, with many mild or asymptomatic infections, which has been observed in only around 15\% of infected individuals [13], or, more likely, it suggests a limited capacity of the surveillance system to detect cases. Limited surveillance in the Salemata district is potentially due to difficult access to health facilities. Indeed, the Salemata district is the most remote area of the region, without sentinel sites, in contrast to the Kedougou and Saraya districts, which have more robust surveillance.

The elevated exposure to CHIKV among human populations living in the rural Kedougou area suggests a high spillover risk from sylvatic into rural or domestic transmission cycles during amplification years. Particularly, gold mining sites that attract a large number of highly mobile individuals may act as hotspots for the emergence and dissemination of new CHIKV strains. Given the abundance of CHIKV vectors in the Kedougou region, the weakness of surveillance systems, and the mass human migrations, strengthening the surveillance system in the Kedougou region, including sensitization on environmental impact of gold mining activities is needed to prevent the establishment of a domestic, human-amplified CHIKV transmission cycle, and the potential global spread of newly introduced virus strains. Finally, due to the potential serologic cross-reactivity between CHIKV and alphaviruses, such as the o'nyong-nyong virus (ONNV), further studies are needed in order to assess the impact of these neglected arboviral diseases in the Kedougou region. However, the lack of ONNV, and other alphavirus detection in mosquito pools collected in the Kedougou region, suggests that the CHIKV seroprevalence that we measure does not represent cross-reactions.

Supplementary Materials: Supplementary materials can be found at http://www.mdpi.com/xxx/s1, File S1: Spatial correlation of village seroprevalence levels. (Reference [44] has been cited in Supplementary Materials).

Author Contributions: Conceptualization, A.A.S., S.C.W. and M.D.; methodology, A.S.; O.F. (Oumar Faye); B.N.; J.C.; software, B.N. and J.C.; validation, A.A.S.; D.M.; A.T.D. and S.C.; formal analysis, A.S.; B.N.; and J.C.; investigation, A.S.; O.N.; O.F. (Ousmane Faye); and B.S.; data curation, A.S.; O.N.; and B.S.; writing-original draft preparation, A.S.; J.C.; and B.N.; writing-review and editing, A.A.S.; D.M.; A.T.D.; S.C.; and S.C.W.; visualization, B.N.; funding acquisition, A.A.S.; and S.C.W. All authors have read and agreed to the published version of the manuscript.

Funding: The research was supported by the National Institutes of Health (NIH), Grant Number AI1069145.

Acknowledgments: The authors thank the population, healthcare workers, and medical authorities in Kedougou region for their support and cooperation in conducting this study.

Conflicts of Interest: The authors declare no competing interests. 


\section{Appendix A}

Table A1. Univariable analysis of the association between CHIKV seroprevalence and environmental variables using $3 \mathrm{~km}$ buffers around villages. The models were adjusted for clustering of individuals in villages and rural communities (random intercept).

\begin{tabular}{cccc}
\hline & OR (95\%CI) & $\begin{array}{c}\text { LRT } \\
p \text {-Value }\end{array}$ & AIC \\
\hline Environmental Variables & & & \\
\hline EVI_max (per 0.1 increase) & $1.79(1.22 ; 2.56)$ & 0.002 & 1355 \\
EVI_mean (per 0.1 increase) & $2.84(1.55 ; 5.22)$ & 0.001 & 1352 \\
EVI_sd (per 0.01 increase) & $1.17(1.02 ; 1.31)$ & 0.018 & 1358 \\
NDVI_max (per 0.1 increase) & $2.58(1.71 ; 3.97)$ & $<0.001$ & 1347 \\
NDVI_mean (per 0.1 increase) & $2.14(1.54 ; 3.82)$ & $<0.001$ & 1350 \\
NDVI_sd (per 0.01 increase) & $1.16(1.01 ; 1.30)$ & 0.028 & 1359 \\
MIR_max (per 0.1 increase) & $0.44(0.18 ; 1.08)$ & 0.067 & 1360 \\
MIR_mean (per 0.1 increase) & $0.09(0.03 ; 0.25)$ & $<0.001$ & 1347 \\
MIR_sd (per 0.01 increase) & $0.94(0.72 ; 1.22)$ & 0.638 & 1363 \\
Distance to water bodies (km) & $1.01(1.00 ; 1.03)$ & 0.044 & 1360 \\
Distance to rivers (km) & $1.02(0.99 ; 1.05)$ & 0.196 & 1361 \\
Slope (degree) & $0.73(0.64 ; 0.81)$ & $<0.001$ & 1339 \\
Altitude (meters) & $1.03(0.90 ; 1.18)$ & 0.674 & 1363 \\
Population density per km (log-transformed) & $1.00(1.00 ; 1.00)$ & 0.825 & 1363 \\
Distance to forest (km) & $1.07(0.99 ; 1.16)$ & 0.071 & 1360 \\
Forest area (proportion, per 0.1 increase) & $0.87(0.75 ; 1.01)$ & 0.062 & 1360 \\
Dccessibility (travel time to city per hour increase) & $1.00(1.00 ; 1.00)$ & 0.966 & 1363 \\
\hline Random Intercepts & & & \\
\hline Village only & NA & 0.003 & 1362 \\
Rural community only & NA & 0.094 & 1368 \\
Village and rural & NA & $<0.001$ & 1361 \\
\hline
\end{tabular}

Table A2. Multivariable analysis of the association between CHIK seroprevalence and environmental variables using $3 \mathrm{~km}$ buffers around villages. The models were adjusted for population density (log-scale) and clustering of individuals in villages (random intercept).

\begin{tabular}{cccc}
\hline Environmental Variables & OR $\mathbf{( 9 5 \% C I )}$ & LRT $p$-Value & AIC \\
\hline Population density per $\mathrm{km}^{2}$ (log-transformed) & $0.73(0.64 ; 0.81)$ & $<0.001$ & 1337 \\
\hline
\end{tabular}

Table A3. CHIKV seroprevalence by sex and age group in villages where population density was $>400$ people per $\mathrm{km}^{2}$.

\begin{tabular}{ccccc}
\hline Sexe & Age Group & nb CHIKV_IgG (+) & nb Individual Surveyed & ChikV Seroprevalence Rate \\
\hline \multirow{6}{*}{ male } & $(5-10)$ & 2 & 10 & $20 \%$ \\
& $(10-20)$ & 5 & 22 & $23 \%$ \\
& $(20-40)$ & 10 & 22 & $45 \%$ \\
& $(40-60)$ & 2 & 4 & $50 \%$ \\
female & $>60$ & 0 & 1 & $0 \%$ \\
& Subtotal & 19 & 59 & $32 \%$ \\
\hline & $(5-10)$ & 3 & 11 & $27 \%$ \\
& $(10-20)$ & 3 & 16 & $19 \%$ \\
& $(40-60)$ & 2 & 18 & $33 \%$ \\
& $>60$ & 1 & 3 & $50 \%$ \\
& Subtotal & 1 & 2 & $20 \%$ \\
\hline
\end{tabular}


A

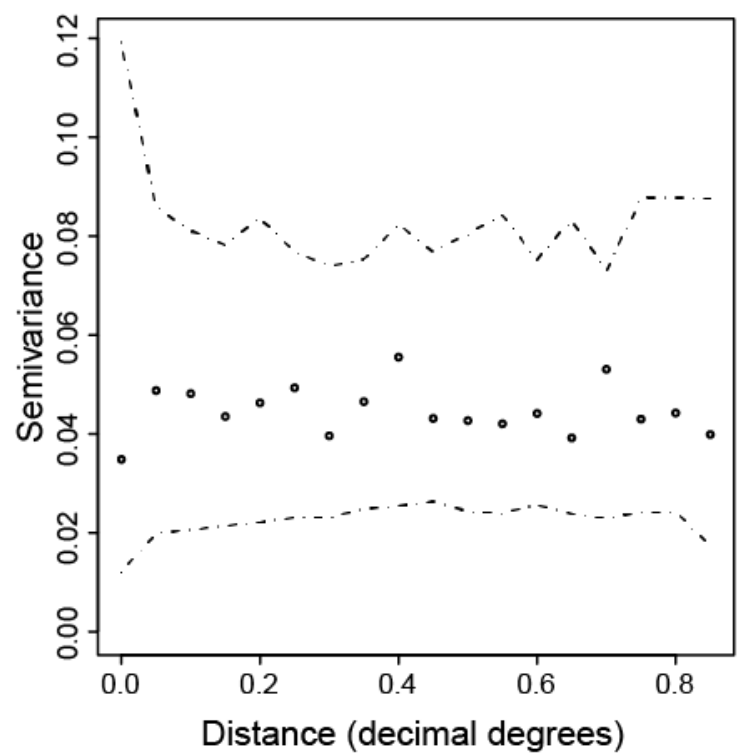

B

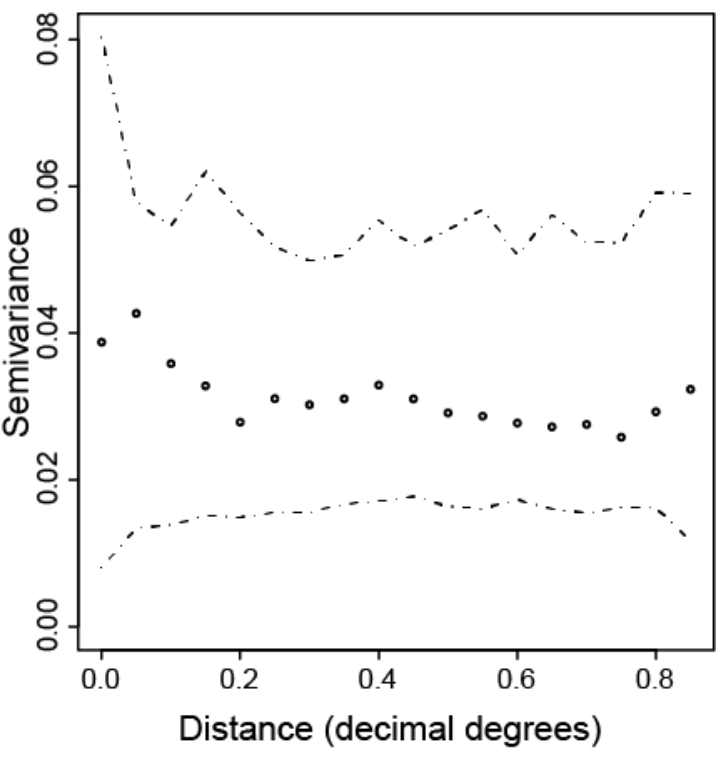

Figure A1. (A) Semivariogram of CHIKV village prevalence and (B) village random effects adjusting for log-transformed population density. Envelopes to assess significance of spatial dependency were computed by simulating 1000 permutations.

\section{References}

1. Schuffenecker, I.; Iteman, I.; Michault, A.; Murri, S.; Frangeul, L.; Vaney, M.C.; Lavenir, R.; Pardigon, N.; Reynes, J.M.; Pettinelli, F.; et al. Genome microevolution of chikungunya viruses causing the Indian Ocean outbreak. PLoS Med. 2006, 3, e263. [CrossRef] [PubMed]

2. Ross, R.W. The Newala epidemic. III. The virus: Isolation, pathogenic properties and relationship to the epidemic. J. Hyg. 1956, 54, 177-191. [CrossRef] [PubMed]

3. Powers, A.M.; Brault, A.C.; Shirako, Y.; Strauss, E.G.; Kang, W.; Strauss, J.H.; Weaver, S.C. Evolutionary relationships and systematics of the Alphaviruses. J. Virol. 2001, 75, 10118-10131. [CrossRef] [PubMed]

4. Deller, J.J., Jr.; Russell, P.K. An analysis of fevers of unknown origin in American soldiers in Vietnam. Ann. Intern. Med. 1967, 66, 1129-1143. [CrossRef]

5. McGill, P.E. Viral infections: Alpha-viral arthropathy. Baillieres Clin. Rheumatol. 1995, 9, 145-150. [CrossRef]

6. Adebajo, A.O. Rheumatic manifestations of tropical diseases. Curr. Opin. Rheumatol. 1996, 8, 85-89. [CrossRef]

7. Althouse, B.M.; Guerbois, M.; Cummings, D.A.T.; Diop, O.M.; Faye, O.; Faye, A.; Diallo, D.; Sadio, B.D.; Sow, A.; Faye, O.; et al. Role of monkeys in the sylvatic cycle of chikungunya virus in Senegal. Nat. Commun. 2018, 9, 1046. [CrossRef]

8. Ligon, B.L. Reemergence of an unusual disease: The chikungunya epidemic. Semin. Pediatr. Infect. Dis. 2006, 17, 99-104. [CrossRef]

9. Diallo, M.; Thonnon, J.; Traore, L.M.; Fontenille, D. Vectors of Chikungunya virus in Senegal: Current data and transmission cycles. Am. J. Trop. Med. Hyg. 1999, 60, 281-286. [CrossRef]

10. Volk, S.M.; Chen, R.; Tsetsarkin, K.A.; Adams, A.P.; Garcia, T.I.; Sall, A.A.; Nasar, F.; Schuh, A.J; Holmes, E.C.; Higgs, S.; et al. Genome-scale phylogenetic analyses of chikungunya virus reveal independent emergences of recent epidemics and various evolutionary rates. J. Virol. 2010, 84, 6497-6504. [CrossRef]

11. Barrett, A.D.T.; Weaver, S.C. Arboviruses: Alphaviruses, flaviviruses and bunyaviruses. In Medical Microbiology, 16th ed.; Greenwood, D., Slack, R.C.B., Peutherer, J.F., Eds.; Churchill Livingstone: London, UK, 2002; pp. 484-501.

12. Brooks, G.F.; Butel, J.S.; Morse, S.A. Human arboviral infections. In Jawetz. Melnick and Adelberg's Medical Microbiology, 23rd ed.; Mc Graw Hill: Singapore, 2004; pp. 514-524.

13. Alessandra, L.P.; Alessia, L.; Eleonora, C.; Gianguglielmo, Z.; Massimo, C. Chikungunya virus, epidemiology, clinics and phylogenesis: A review. Asian Pac. J. Trop. Med. 2014, 7, 925-932. 
14. Thonnon, J.; Spiegel, A.; Diallo, M.; Diallo, A.; Fontenille, D. Chikungunya virus outbreak in Senegal in 1996 and 1997. Bull. Soc. Pathol. Exot. 1999, 92, 79-82. [PubMed]

15. Pfeffer, M.; Dobler, G. Emergence of zoonotic arboviruses by animal trade and migration. ParasitVectors 2010, 3, 35. [CrossRef]

16. Devaux, C.A. Emerging and re-emerging viruses: A global challenge illustrated by Chikungunya virus outbreaks. World J. Virol. 2012, 1, 11-22. [CrossRef] [PubMed]

17. Weaver, S.C.; Reisen, W.K. Present and Future Arboviral Threats. Antiviral Res. 2010, 85, 328-345. [CrossRef] [PubMed]

18. Lanciotti, R.S.; Kosoy, O.L.; Laven, J.J.; Panella, A.J.; Velez, J.O.; Lambert, A.J.; Campbell, G.L. Chikungunya virus in US travelers returning from India, 2006. Emerg. Infect. Dis. 2007, 13, 764-767. [CrossRef] [PubMed]

19. Pistone, T.; Ezzedine, K.; Boisvert, M.; Receveur, M.C.; Schuffenecker, I.; Zeller, H.; Lafon, M.E.; Fleury, H.; Malvy, D. Cluster of chikungunya virus infection in travelers returning from Senegal, 2006. J. Travel Med. 2009, 16, 286-288. [CrossRef] [PubMed]

20. Moro, M.L.; Gagliotti, C.; Silvi, G.; Angelimni, R.; Sambri, V.; Rezza, G.; Massimiliani, E.; Mattivi, A.; Grilli, E.; Finarelli, A.C.; et al. Chikungunya virus in north-eastern Italy: A seroprevalence survey. Am. J. Trop. Med. Hyg. 2010, 82, 508-511. [CrossRef]

21. Grandadam, M.; Caro, V.; Plumet, S.; Thiberge, J.M.; Souarès, Y.; Failloux, A.B.; Tolou, H.J.; Budelot, M.; Cosserat, D.; Goffart, I.L.; et al. Chikungunya Virus, Southeastern France. Emerg. Infect. Dis. 2011, 17, 910-913. [CrossRef]

22. Powell, J. New contender for most lethal animal. Nature 2016, 540, 525. [CrossRef]

23. Reiter, P. Aedes albopictus and the world trade in used tires, 1988-1995: The shape of things to come? J. Am. Mosq. Control. Assoc. 1998, 14, 83-94. [PubMed]

24. Medlock, J.M.; Hansford, K.M.; Schaffner, F.; Versteirt, V.; Hendrickx, G.; Zeller, H.; Bortel, W.V. A review of the invasive mosquitoes in Europe: Ecology, public health risks, and control options. Vector Borne Zoonotic Dis. 2012, 12, 435-447. [CrossRef] [PubMed]

25. Bres, P.; Chambon, L.; Pape, Y.; Michel, R. Isolement de plusieurs souches d'arbovirus à partir des glandes salivaires de chauves-souris. Bul. Soc. Med. Afr. Noire. Langue. Fr. 1963, 8, 710-712.

26. Robin, Y.; Bres, P. Arboviruses in Senegal. Current status. Bull. Soc. Med. Afr. Noire. Lang. 1969, 14, 722-728.

27. Roche, S.; Robin, Y. Human infections by CHIK virus in Rufisque (Senegal). Bul. Soc. Med. Afr. Noire. Langue. Fr. 1966, 12, 490-496.

28. Saluzzo, J.F.; Cornet, M.; Digoutte, J.P. Outbreak of a CHIK virus epidemic in western Senegal in 1982. Dakar Med. 1983, 28, 497-500.

29. Monlun, E.; Zeller, H.; Le Guenno, B.; Traoré, L.M.; Hervy, J.P. Surveillance de la circulation des arbovirus d'intérêt médical dans la région du Sénégal Oriental (1988-1991). Bull. Soc. Pathol. Exot. 1993, 86, 21-28.

30. Cornet, M.; Robin, Y.; Chateau, R.; Héme, G.; Adam, C.; Valade, M.; Gonidec, G.L.; Jan, C.; Renaudet, J.; Dieng, P.L.; et al. Isolement d'arbovirus au Sénégal oriental à partir de moustiques (1972-1977) et notes sur l'épidémiologie des virus transmis par les Aedes, en particulier du virus Amaril. Cah. O.R.S.T.O.M. Sér. Ent. Méd. Parasitol. 1979, 17, 149-163.

31. Diallo, M.; Sall, A.A.; Moncayo, A.C.; Ba, Y.; Fernandez, Z.; Ortiz, D.; Coffey, L.L.; Mathiot, C.; Tesh, B.B.; Weaver, S.C. Potential role of sylvatic and domestic African mosquito species in dengue emergence. Am. J. Trop. Med. Hyg. 2005, 73, 445-449. [CrossRef]

32. CRORA (Centre Collaborateur OMS de Référence et de Recherche pour les Arbovirus et Virus de Fièvres Hémorragiques). Available online: http://www.pasteur.fr/recherche/banques/CRORA/virus (accessed on 1 October 2017).

33. Sow, A.; Faye, O.; Diallo, M.; Diallo, D.; Cheng, R.; Faye, O.; Diagne, C.T.; Guerbois, M.; Weidmann, M.; Ndiaye, Y.; et al. Chikungunya Outbreak in Kedougou, Southeastern Senegal in 2009-2010. Open Forum Infect Dis. 2018, 5. [CrossRef]

34. Agence nationale de la Démographie et de la Statistique (2015). Service Régional de la Statistique et de la Démographie de Kédougou. Rapport Annuel de la Situation Economique et Régionale. Kedougou, Sénégal. Aboubacar Sédikh BEYE. 138p. Available online: http://www.ansd.sn/ressources/ses/SES-Kedougou-2013.pdf (accessed on 17 July 2017). 
35. Traore, L.M.; Fontenille, D.; Zeller, H.G.; Mondo, M.; Diallo, M.; Adam, F.; Eyraud, M.; Maiga, A.; Digoutte, J.P. Surveillance for yellow fever virus in eastern Senegal during 1993. J. Med. Entomol. 1996, 33, 760-765. [CrossRef] [PubMed]

36. NASA EOSDIS. Land Processes DAAC, USGS Earth Resources Observation and Science (EROS) Center, Sioux Falls. Available online: https://lpdaac.usgs.gov (accessed on 15 September 2017).

37. Hay, S.I.; Tatem, A.J.; Graham, A.J.; Goetz, S.J.; Rogers, D.J. Global environmental data for mapping infectious disease distribution. Adv Parasitol. 2006, 62, 37-77. [PubMed]

38. Hansen, M.C.; Potapov, P.V.; Moore, R.; Hancher, M.; Turubanova, S.A.; Tyukavina, A.; Thau, D.; Stehman, S.V.; Goetz, S.J.; Loveland, T.R.; et al. High-Resolution Global Maps of 21st-Century Forest Cover Change. Science 2013, 342, 850-853. [CrossRef] [PubMed]

39. Farr, T.G.; Kobrick, M. Shuttle Radar Topography Mission produces a wealth of data. Am. Geophys. Union Eos 2000, 81, 583-585. [CrossRef]

40. Lunn, D.J.; Thomas, A.; Best, N.; Spiegelhalter, D. WinBUGS-A Bayesian modelling framework: Concepts, structure, and extensibility. Stat. Comput. 2000, 10, 325-337. [CrossRef]

41. Diallo, D.; Sall, A.A.; Buenemann, M.; Chen, R.; Faye, O.; Diagne, C.T.T.; Faye, O.; Ba, Y.; Dia, I.; Watts, D.; et al. Landscape Ecology of Sylvatic Chikungunya Virus and mosquito Vectors in Southeastern Senegal. PLoS Negl. Trop. Dis. 2012, 6, e1649. [CrossRef]

42. The WorldPop Demography Project. Available online: http://www.worldpop.org.uk/ (accessed on 15 September 2016).

43. Sow, A.; Faye, O.; Diallo, D.; Chen, R.; Faye, O.; Diagne, C.T.T.; Ndiaye, Y.; Senghor, C.S.; Abdourahmane Faye, A.; Diop, O.M.; et al. Re-emergence of Yellow fever in Kedougou, Southeastern Senegal in 2010-2011. Int. J. Sc. Res. 2017. [CrossRef]

44. Travel Time to Major Cities: A Global Map of Accessibility. Available online: http://bioval.jrc.ec.europa.eu/ products/gam/index.htm (accessed on 15 September 2018).

(C) 2020 by the authors. Licensee MDPI, Basel, Switzerland. This article is an open access article distributed under the terms and conditions of the Creative Commons Attribution (CC BY) license (http://creativecommons.org/licenses/by/4.0/). 